\title{
TEACHING WRITING
}

\author{
Majlinda Lika \\ PhD candidate, ALBANIA, e-mail: Imajlinda@yahoo.com
}

\begin{abstract}
Nowadays, the need to communicate through writing is significantly increasing as a result of a more intense human and institutional interaction. The globalization and the development of the information technology is another factor that urges the need to exchange information and meet the needs through written communication. The competence of writing remains on the core of language consolidation as regarded in the Albanian language curricula. According to national and international reports, Albanian students face difficulties in their ability to express themselves in writing. This article aims to analyze these difficulties and address issues that make this process complex for students. Data for this study were collected through analysis of four students' essays, taken by students taught with the "process approach" and the "product approach". Additionally, interviews were carried out with focus groups organized with fifth graders of a 9-year school in Tirana. The findings prove that pupils, who have been taught with the "process approach", have better attainment compared to pupils taught with the "product approach". According to pupils' answers, teachers in public schools continue to teach writing in the traditional way. This kind of approach limits teachers' access to monitor and assist pupils in their efforts to improve. The study focuses on the evolution of the writing process as well as the strategies and techniques used during these stages. The study will serve teachers of Albanian language to review their approach to teaching writing and consider the benefits of the constructivist approach, that of teaching and learning to write in process.
\end{abstract}

Keywords: constructivist approach, writing skills, writing as a product, writing as a process, the achievement of pupils

\section{INTRODUCTION}

Writing is a form of expression that needs logical engagement in structuring thoughts and ideas in print. Being able to write does not belong only to gifted people, but everyone that wants to fulfill needs and express viewpoints. Writing is a skill that can be taught. According to Nunan writing is a 'complex, cognitive process that requires sustained intellectual effort over a considerable period of time'. Writing is a tool that enables formal and informal communication between people. Recently the concept has merged with reading. Studies show that advantages of people, who are literate, are significantly higher in employment, integration and the success achieved, compared to people who are less trained in this skill. Writing has been defined as structuring of ideas and point of views in print. Writing instruction has shifted from spelling, grammar, and other writing conventions, to a holistic view emphasizing writing as a recursive process. A good product relies on a good process. As Hillocks and Murray state in their study 'writing is seen as a recursive process in which writers have the opportunity to plan, draft, edit, and revise their work'.

In this paper we will discuss the differences between a process approach and the traditional approach to teaching writing. Also the difficulties fifth-grade pupils face in expressing their ideas in writing will be 
identified and analyzed. The methodological approach used by teachers will be discussed. The paper will show how the process approach is applied to overcome specific writing difficulties.

\section{BACKGROUND}

According to National Report, 2014 carried out by the National Agency of Exams in Albania $33.95 \%$ of pupils have gained 0 points when required to make a description based on certain keywords. The same situation has been reported in 2015 report where fifth grade pupils who were tested on the same essay, have remained almost at the same level of skills. $33 \%$ of fifth grade students have gained 0 points. The performance has worsened when fifth graders were required to write an argumentative essay. The report indicates that $43 \%$ of pupils were evaluated with 0 points.

\section{METHODOLOGY}

Data regarding the quality of pupils' performance were obtained through analysis of sample essays generated by pupils in tests. Evidence from two essays written by fifth graders was analyzed. The essays were taken from pupils who were randomly selected in a low-secondary public school in Tirana, because we thought that would affect the objectivity of the study as well as the generalization of the approach. The pupils were taught writing based on the product approach. Two other essays were randomly taken from two fifth graders who attend a private school in Albania and learn writing based on the process approach. It should be noted that writing approaches are implemented differently in private and public schools even though curricula requirements are the same, because of the fact that teachers in private schools get systematic training and benefit of the number of pupils in classes, which is much lower compared to public schools. Pupils involved in the study learn the Albanian language as their mother tongue for 5 years, respectively 5 hours per week. The writing samples were analyzed based on indicators that derive from curricula requirement of and relate to the aspects of structure, ideas, organization, cohesion/coherence, vocabulary and grammar. Findings from essays were analyzed in qualitative and descriptive perspective. The aim was to analyze pupils' barriers in writing and identify the implementation of curricula requirement. Also, interviews were carried out with three focus groups with fifth graders from a public low-secondary school in Tirana, taught based on the traditional approach. The purpose of the interview was to gain information about the way pupils were taught writing. Based on pupils answers implications were reached upon the practices teachers implement and the difficulties the pupils face while mastering this skill.

\section{WRITING APPROACHES}

\subsection{Writing as a product}

Some teachers ask pupils to write, while others teach them how to write. There is a big difference between these two approaches. Can we teach pupils to write? Should we focus on the product or the process? Does a well supervised process lead to a qualitative product? What are the reasons that some students manage to express their ideas in writing and others fail? Does it relate to the lack of thoughts or is it simply about difficulties in relating ideas to each-other? What strategies and techniques do teachers apply, and are they sufficient to skill the pupils?

Different studies show that writing as a product relies mainly on models and restricts pupils' creativity. It is concerned with the final result of the writing process. Text features are important and students follow certain patterns to express their ideas. The lack of the process development is emphasized by White (1988). What the model does not demonstrate, is how the original writer arrived at that particular product. In other words, it gives no indication of process. To reinforce the definition of the process-based approach, we will quote Murray (1972) 'product-based evaluation does not improve writing skills and by implementing it in our classes we do not help our pupils to learn writing'.

\subsection{Writing as process}

Writing as a process is an innovative approach that follows the traditional approach, writing as a product. The main goal of the process approach is to teach pupils generate, plan ideas, take into consideration the audience they are writing for, draft and redraft in order to produce a final written paper that expresses ideas in a meaningful and clear way. Writing as a process relates to learning and making progress while learning. To teach pupils write in process means to activate their existing knowledge using specific techniques, to enlarge their schemas and perspectives on different concepts, organize and connect their ideas, ensure cohesion and coherence of thoughts, express themselves clearly for a specific audience, revise drafts and improve them. 
(Applebee, 1986) considers writing as a process a method of thinking that facilitates students' analyses and organization of ideas. While Murray's views relate to the importance it should be paid to the practice of writing. According to Murray we cannot learn about a process only by talking about it, but by doing it. Teachers who use this approach provide time for pupils to learn about the topic and then express their points of views on the issue. Scaffolding and feedback is given in order to help pupils to progress in this language skill. Many researchers have found that the process writing approach has a significant impact on pupil's performance compared to product writing approach. (Krashen, 1984) sees writing a moment of reflection upon thoughts and ideas as he states: 'many good writers employ a recursive, non-linear approach — writing of a draft may be interrupted by more planning, and revision may lead to reformulation, with a great deal of recycling to earlier stages' The opportunity to revise and improve the product is encouraged to the point where the pupil has achieved his best. Another perspective to be considered at this stage, is the idea that the process helps the student to self-assess increase motivation and consolidate skills of learning how to learn. The writing process goes through several stages, and Murray defines three such as: pre-writing, writing and post-writing. What happens during these stages and what cognitive skills are activated?

\subsubsection{Pre-writing stage}

Pre-writing stage is the most crucial moment in the process of writing and according to Murray, it occupies $85 \%$ of the time during which the student gathers, selects, balances and integrates the ingredients to eachother until best product is achieved and the student uses all his capacity and potential to get skilled. Some pupils start to write directly in the notebook without going through the stage of pre-writing. Starting to write with spontaneous unrelated ideas that come at different times during the writing would endanger the clarity and the cohesion of writing.

\subsubsection{Pupils answers on how pre-writing is taught}

Focus group nr 1: Pre-writing activities relate mainly to spoken activities. The teacher talks and we listen. Then she asks us to fill in the gaps. Sometimes, I find myself not listening to the teacher, but thinking of something else. It is difficult to understand what the teacher is saying if you are not following. The writing activity is not written in class, but the teacher gives it as a homework activity.

Focus group nr 2: I don't like writing. I feel like I am blocked. I am short of ideas. Sometimes I write down two lines and I don't know what to write further. We discuss questions at class, but at home I forget them, or sometimes I recall some of them. Writing happens during an hour because the teacher has to explain a new lesson.

Focus group nr 3: Teachers ask questions but they answer by themselves mostly, because sometimes we do not have this information. Teachers tell us to ask parents, but they are busy and cannot help me.

\subsubsection{Pupils answers analysis}

Students state that during classes the aspect of idea generation and structural elements is not given proper attention. These elements are mainly discussed theoretically during the lessons, but are not implemented in practice. These statements indicate that pupils aren't given scaffolding to enrich and arrange their ideas and they have difficulty in expressing them clearly and logically.

\subsubsection{Writing}

As Murray emphasizes 'writing is the act of producing the first draft; it is considered the fastest and most frightening, process, because it is where ideas come to life. The ideas and perspectives are no longer at the pupil's brains but they come alive even though they are not the ultimate ones. This stage is considered as the mechanical part of the process. Referring to pupils' answers this is the only written stage they perform. 'During the lesson the teacher talks about writing and we listen, and we have to do it as a homework activity'. The stage of writing occurs mainly as a homework activity and it is not a derivate of the pre-writing stage. In this context problems have been raised relating lack of ideas, poor organization and poor vocabulary.

\subsubsection{Post-writing}

According to Murray post-writing is the moment of reviewing the purpose, the content and the form of writing. Moreover, this stage relates to further researching, rethinking, redesigning, rewriting - and finally correcting line by line, trying to give to every word a proper meaning. Time devoted to this stage is $14 \%$ of the remaining time from the process. During this stage the pupils have the opportunity to reflect on the product, review and revise their ideas. Scaffolding is provided until the product reaches clarity, structure, cohesion and coherence. Post writing is a stage of self-assessment and learning that helps the pupils to consolidate their writing skills. Some studies restrict the role of the teacher. (Badger \& White, 2000) view the teachers only as facilitators, not as motivators. While other studies focus on the importance of the feedback teachers 
provide for the pupils. Teachers' comments and suggestion serve as an orientation for the pupil to learn and reflect upon the product. They prioritize also meaning level to other aspects of writing. Zamel (1985) urges setting priorities in teachers 'comments and suggestions for revision and encouraging pupils to address meaning-level concerns before others.

\subsubsection{Pupils' answers on how post-writing stage is developed.}

Focus group nr 1: Post- writing, there is not such stage. Two or three pupils are asked to read, that is all. The teacher makes interventions that relate to poor pronunciations.

Focus group $\mathrm{nr}$ 2: The main comments made verbally by the teacher are: Too short! I liked it! Well done! I didn't understand anything.

Focus group nr 3: The teacher does not tell us to rewrite. When rarely she corrects our homework she corrects grammar accuracy. Most of my writing is unfinished; I don't know what to write. The teacher gives ideas, but I can't connect them. We mainly do the writing at home and the teacher does not correct our homework, because there are many pupils and there is no time.

\subsubsection{Pupils' answers' analysis}

Pupils' answers prove that correction of writings mostly doesn't happen or when it happens it mainly relates to the grammar and spelling errors, not to the ideas and meaning. Writing as an activity happens without teachers monitoring and support. The time devoted to develop the skill is limited. In this context the teacher does not fulfil the role of facilitator, supporter and motivator of the student in the process of learning. In this scenario teachers cannot adapt teaching method to the level and needs of students.

\section{ESSAYS FOR STUDY}

In this section an analysis of four different writing samples will be developed; the writing difficulties of the pupils will be reviewed. Two essays from fifth graders who have been taught with the product approach and two essays from fifth graders who have been taught with the process approach will be discussed. Process approach techniques will be represented as ways of helping pupils overcome their writing difficulties

\subsection{Essay sample one}

\section{Descriptive essay, (product approach)}

I was very sad when I got hurt. I was sad when I didn't play with my friends. I was sad when I wasn't playing out with my friends. One day I am sad when I have gotten a bad mark. Once I got sad, when my mum shouted me

\subsubsection{Pupil performance}

The text does not respond to the request. The pupil is required to "describe" while the sentences have narrative character, which means that the pupil has difficulty in understanding the question. The tone of the writing is characterized by narrative elements and not descriptive ones as required.

The structure: The entire text lacks a structure and elements such as: the introduction, the development and the conclusion. It is characterized by fragmented sentences that do not relate and do not fulfil the purpose of description. One reason may be that the pupil might have not paid attention to the request because he confesses with few sentences different moments of negative experiences.

Cohesion-coherence: Writing lacks cohesion and coherence, the pupil faces difficulties in connecting ideas and fails to describe a negative experience in his life. Repetition of the form "I was very sad", ruins the descriptive character of writing and corresponds to the register of spoken language.

Lexicon: Writing is built based on frequent repetition and a poor vocabulary. Adjectives and descriptors that characterize descriptive writings are not used. The verbal expression "I was very sad" used 5 times repeatedly in 5 sentences, influences writing quality. Writing does not have a certain tone that draws reader's attention. The linking words are not integrated in the text and ideas do not relate to each other.

Grammar: Sentence building poses problems in adjusting the tenses of the verbs within the sentences. The sentence "One day I am sad when I have gotten a bad mark" represents structural problems that affects sentence comprehension. The pupil has difficulties in using the tenses of the verbs and adjusting them accordingly to the type of writing. Semantic meaning of past simple tense is not consolidated. "I was sad when I wasn't playing out with my friends". The pupil shows problems of using and adapting the tenses of the verbs to the development of events. 


\subsection{Essay sample two}

Descriptive essay, (product approach)

It was 18 of January 2015, when my grandfather passed way. That day was the worst day of my life. He was the dearest person to me. The day my mum came to Tirana, I found out. They had kept it hidden from me, because they wanted me not to get sad. Always I remember and I will never forget him.

\subsubsection{Pupil performance}

The structure: The description does not have a structure. The whole text is organized in a single paragraph. The last sentence has a declarative tone and is not a synthesis of the ideas evolved in writing.

Cohesion-coherence: Writing has a certain chronology. The reader gets most of the information about the event but some elements are missing. Thus, the pupil is precise about the time and the problem, but misses the place where the event occurs and does not mention all the characters. Understandably, it is a different place from Tirana, but it is not clear in which city the event takes place. The second sentence: 'That day was the worst day of my life' is a conclusion, which comes directly after the presentation of the major event. The sentence 'He was the dearest person to me' does not relate to the previous. The linkers that enable natural transition from one paragraph to the other are not used. The overall writing is incomplete and lacks details that facilitate the comprehension. The pronoun 'They' in the sentence 'They had kept it hidden' is implicit as it is unclear to whom it refers.

Lexicon: Writing in general has a narrative and not a descriptive voice. The vocabulary does not justify the descriptive nature of writing, and vocabulary is characterized by repetitive pronouns. Descriptive features such as descriptive adjectives have not been used.

Grammar: It is obvious that pronouns are used frequently and occasionally, they lose reference. In the last sentence "I will never forget him." The direct object refers to grandfather, who is not cited in the previous sentence, but in the first sentence of the text. Verbs do not express the relevant meaning of the sentences. The verb "came", might have been replaced by the verb "return". The adverb "always" is not placed correctly in the sentence, because it does not follow the right order and the tense of the verb "I remember" is wrong.

\subsubsection{Summary of pupils' performance taught based on the product approach:}

Pupils are not clear on the descriptive features of a text

They are not aware of the style and the vocabulary that characterizes the descriptive texts

They confuse the particularities of a descriptive text with those of a narrative one

They face difficulties in structuring ideas

They encounter problems of sentence structure

They lack ideas on descriptive topics

They demonstrate poor vocabulary and repetition that affects the quality of writing

They show thoughts' ambiguity

They lack coherence and cohesion

They face difficulties in using grammar correctly

\subsection{Essay sample three}

Descriptive essay (process approach): Describe an unhappy moment in your life.

Life is full of happy and unhappy moments. Unfortunately, during life we have to face some unhappy ones. I am going to describe a bad moment of my life that had an impact on me.

It was Monday. I got up as usually and I got ready for school. I had the delicious breakfast my mum had prepared for me and I left for school. The day was sunny and that gave me a nice feeling. Suddenly, I recalled that after school I had to buy the bouquet of flowers for my grandma. It was her birthday and I was looking forward to it. I wanted to make her a surprise. She had always surprised me and now it was my turn. I loved her very much. She was the world to me.

After the classes, I stopped at the florist and bought the bouquet. It was beautiful and I hoped grandma would like it too. I rushed at my grandma's home. I knocked at the door and I was waiting for grandma to appear behind the door and give me her sweet smile and warm hug. I knocked again, but nobody answered. 
I started to get worried. Negative thoughts started to go through my head. I knocked over and over again, and then a neighbour opened her window and explained to me what had happened. My grandma had fainted and she had been transported to the hospital by an ambulance.

I was shocked. I couldn't believe what had happened. Grandma's neighbour wrote the hospital address and I rushed to the hospital .While driving to the hospital I was praying for her and I couldn't stop my tears. When I arrived, she was at the recovery room. My mum was taking care of her. I hugged her endlessly and she gave me her big smile back.

I put the flowers on the bed and I thanked God.

\subsubsection{Pupil performance}

The structure: Organisation reflects the purpose of the writing. The story is balanced and there is an attempt to create pace. The paragraphs are well build and they support the whole structure of writing. Closing is short, but significant.

Cohesion and coherence: The description ensures logical connection between paragraphs and events. The event discussed follow a certain chronology and coherence. Adverbs and conjunctions are used to establish cohesion within the paragraphs. Writing has the proper clarity and the reader can digest the information easily.

Lexicon: Te text is rich of descriptive elements that make the description attractive. The language is simple and understandable.

Grammar: The sentences are short, correctly constructed and the grammar aspect is consolidated. Punctuation is used to convey and clarify meaning.

\subsection{Essay sample four}

Argumentative essay, (process approach): Why do you like playing?

Playing occupies an important part of my life. Childhood can't be imagined without playing. Like other children I spend a great amount of time playing and having fun. Why I do I like playing?

First of all I like playing because it entertains me a lot. There is a lot of adrenaline, and negative energy gets out of my body.

Second, play time it is a great opportunity to socialize and spend some quality time with my friends.

Third, I learn about other cultures through play. I like playing because it disciplines me to follow rules and rules are important. Playing makes my life more beautiful.

On the other hand there are some people, who are addicted to games and that is a bad thing. Best way is to find balance between responsibilities and entertainment.

To conclude, playing is great because it helps me grow and enjoy my life

\subsubsection{Pupil performance}

The structure: The organization of the text is well established. Linking words are used appropriately. Paragraphs are well structured. Tenses and persons are accurate and consistent with noun verb agreement.

Cohesion and coherence: The topic has been reviewed from different perspectives, which proves of a variety of thought and ideas. Ideas relate naturally to each other, coherence has been met and arguments are convincing to the reader. The position of the pupil is explicit.

Lexicon: Vocabulary is chosen to add interest, clarity and to introduce opinion or persuasion.

Grammar: There aren't any grammatical inaccuracies. Spelling and punctuation is used correctly.

\subsubsection{Summary of pupils' performance taught based on the process approach:}

Pupils chose sentence structures that have a specific effect upon the reader

They use different narrative techniques to maintain the reader's interest.

They use varied vocabulary to create effects.

They combine effectively elements of description and action.

They write well structured essays. 
They show clarity and organization of ideas.

They show coherence and cohesion of thoughts and ideas.

They demonstrate a correct use of grammar.

\section{TEACHING WRITING}

\subsection{Activity for developing pre-writing stage}

Topic of the essay: Do you prefer living in the city or in the country side?

The following activity is based on a process approach and addresses techniques for activating and organizing ideas. Some of the techniques that serve to elicit and organize pupils' ideas are questioninganswering technique, brainstorming and Venn diagram.

First step: By using brainstorming technique the teacher helps pupils to activate and share their experiences, prior knowledge and asks to write them on their notebook. Ex.: What are some of the benefits of living in the city? What are some of the benefits of living in the country? What do you like most about living there?

Second step: The teacher plays the role of the facilitator by setting indicators and criteria and enhancing students perspectives on the topic such as: security; quality of service; pollution; entertainment; employment; cultural life; social life; etc. For each indicator respectively the students define advantages and disadvantages and support them with facts and evidences.

Third step: The teacher introduces Venn diagram technique to compare advantages and disadvantages of living in the countryside and the city. After deciding and positioning themselves the students compare facts, make analysis based on certain logic, reach conclusions and defend their points of view.

Fourth step: The teachers ask students to illustrate and back up with examples, facts and evidence the information they provide.

Fifth step: Characteristics of the structure are discussed and students advance through the writing stage.

\section{SUMMARY}

The major general finding from the research on teaching writing, is that student achievement is higher when the teaching approach emphasizes writing as a process rather than writing as a product (Parson 1985).Data from the interviews prove that pupils in public schools are not familiar with the process approach, strategies and techniques that are used during these stages. In this context pupils are left alone in their efforts to learn. According to their answers teaching is not taught, but is mainly assessed, and the teachers suggestions relate to accuracy, while very little attention is given to the whole process of writing.

Essays analysis proves that there is a big difference in performance between pupils that learn writing as a process compared to pupils who learn writing based on the product approach. Based on these findings, the use of process writing approach is recommended for improving writing skills.

Mastering the approach of writing as a process will refine pupils' cognitive skills. In addition to consolidating critical thinking, problem solving and decision making, it should be noted that the acquisition of these strategies empowers students to express themselves in writing. Writing as a process offers a great opportunity for learning and making progress as pupils are given time and support by teachers to enrich and enlarge their schemas.

\section{REFERENCE LIST}

Agjensia Kombëtare e Provimeve, (2014). Raport publik Vlerësimi Kombëtar për lëndët: Gjuhë shqipe, Matematikë, Dituri natyre, klasa 3 dhe 5 . Tiranë

Agjensia Kombëtare e Provimeve, (2015). Vlerësimi i arritjeve të nxënësve të klasës së 3- të dhe të 5- të. Tiranë

Instituti i Zhvillimit të Arsimit, 2010. Mother Tongue Curricula for low secondary schools in Albania, Tiranë 
Krashen, S. D. (1984). Writing: Research, theory and applications

Murray, D. M. (1972). Teaching writing as a process not product. The Leaflet, November, (11-14)

Nunan, D. (1996). A Language Teaching Methodology. London, Longman

Parson, G. (1985). Hand in hand: the writing process and the microcomputer. Juneau, AK: Alaska State Department of Education.

White, R. V.(1988). Process and Product. In P. Robinson (Ed) Academic Writing. ELT Document, 129 (4-16)

Zamel, Vivian. Responding to Student Writing.' TESOL Quanerly 19 (1985) (79-101) 